\title{
Airway inflammatory response to ozone in subjects with different asthma severity
}

\author{
B. Vagaggini, S. Carnevali, P. Macchioni, M. Taccola, E. Fornai, E. Bacci, M.L. Bartoli, \\ S. Cianchetti, F.L. Dente, A. Di Franco, D. Giannini, P.L. Paggiaro
}

Airway inflammatory response to ozone in subjects with different asthma severity. B. Vagaggini, S. Carnevali, P. Macchioni, M. Taccola, E. Fornai, E. Bacci, M.L. Bartoli, S. Cianchetti, F.L. Dente, A. Di Franco, D. Giannini, P.L. Paggiaro. (C)ERS Journals Ltd 1999. ABSTRACT: The aim of this study was to evaluate whether ozone exposure induces a similar airway inflammatory response in subjects with different degrees of asthma severity.

Two groups of asthmatic subjects were studied: seven with intermittent mild asthma not requiring regular treatment (group $A$ ); and seven with persistent mild asthma requiring regular treatment with inhaled corticosteroids and long-acting $\beta_{2}$-agonists (group B). All subjects were exposed, in a randomized cross-over design, to air or $\mathrm{O}_{3}$ (0.26 parts per million (ppm) for $2 \mathrm{~h}$ with intermittent exercise); subjects in group B withdrew from regular treatment $72 \mathrm{~h}$ before each exposure. Before the exposure, and 1 and $2 \mathrm{~h}$ after the beginning of the exposure they performed a pulmonary function test, and a questionnaire was completed to obtain a total symptom score (TSS). Six hours after the end of the exposure, hypertonic saline (HS) sputum induction was conducted. Sputum cell percentages, eosinophil cationic protein (ECP) and interleukin (IL)-8 concentrations in the sputum supernatant were measured.

TSS significantly increased and forced vital capacity (FVC) and forced expiratory volume in one second (FEV1) significantly decreased after $\mathrm{O}_{3}$ exposure in comparison with air exposure in group $A$, whereas no changes were observed in group $B$ except for a significant decrement of FEV1 2 h after the beginning of $\mathrm{O}_{3}$ exposure. Sputum neutrophil percentage was significantly higher after $\mathrm{O}_{3}$ exposure than after air exposure in both groups (Group A: 70.2\% (28-87) versus 26.6\% (8.6-73.2); Group B: $62.1 \%(25-82.4)$ versus $27.9 \%(14.4-54))$. IL-8 was higher in sputum supernatant collected $6 \mathrm{~h}$ after $\mathrm{O}_{3}$ exposure than after air, only in group $A$. No change due to $\mathrm{O}_{3}$ has been found in sputum eosinophil percentage and ECP concentration in both groups.

In conclusion, the degree of airway response to a short-term exposure to ozone is different in subjects with asthma of different severity. The available data do not allow elucidation of whether this difference depends on the severity of the disease or on the regular anti-inflammatory treatment

Eur Respir J 1999; 13: 274-280.

Epidemiological studies have shown that high ambient concentrations of ozone are strictly associated with the occurrence of acute respiratory symptoms and increased rates of hospital admission in adults and children $[1,2]$. In laboratory studies it has been confirmed that short-term exposure to $\mathrm{O}_{3}$ induces in both healthy and asthmatic subjects a significant decrement in forced vital capacity (FVC) and forced expiratory volume in one second (FEV1), elicits a respiratory discomfort and an increased airway reactivity to methacholine and allergen [3-6]. The pathophysiological background of this airway response is a neutrophilic inflammation of the airways accompanied by an increased level of proteins and mediators as demonstrated by bronchoalveolar lavage (BAL) technique [7]. Although previous studies reported different results regarding the effects on pulmonary function due to $\mathrm{O}_{3}$ exposure in normal and asthmatic subjects $[4,8]$, more recently, other studies have demonstrated that asthmatics have a greater inflammatory
Cardio-Thoracic Dept, Respiratory Pathophysiology, University of Pisa, Italy.

Correspondence: B. Vagaggini

U.O. Fisiopatologia Respiratoria

Ospedale Cisanello

via Paradisa 2

56100 Pisa

Italy

Fax: 3950580126

Keywords: Asthma severity

ozone

sputum interleukin- 8

sputum induction

sputum neutrophils

Received: January 151998

Accepted after revision August 151998 response in BAL fluid after $\mathrm{O}_{3}$ exposure $[9,10]$. HILTERMANN et al. [11] showed that 0.4 parts per million (ppm) $\mathrm{O}_{3}$ exposure induced a high sputum neutrophil recruitment in the airways in both normal and asthmatic subjects, the difference between healthy and asthmatics in the percentage of neutrophils being significant.

The aim of the present study was to compare the airway inflammatory response due to $\mathrm{O}_{3}$ between two groups of asthmatic subjects with different degrees of asthma according to international guidelines [12]: group A, subjects with mild intermittent asthma, asymptomatic and without regular treatment; and group B, subjects with mild persistent asthma, requiring regular treatment to control asthma symptoms. To detect the inflammatory response of the airways, the technique of hypertonic saline (HS) induced sputum has been used. It is a reproducible, noninvasive and safe technique [13] and it has been proven to be useful for asthma diagnosis and for disease monitoring [14]. 


\section{Subjects and methods}

\section{Subjects}

Two groups of asthmatic subjects were studied: seven subjects with intermittent mild asthma not requiring regular treatment (group A); seven subjects with persistent mild asthma requiring regular treatment with inhaled corticosteroids (beclomethasone dipropionate $500 \mu \mathrm{g}$ b.i.d) and long-acting $\beta_{2}$-agonist (salmeterol $50 \mu \mathrm{g}$ b.i.d) to control asthma symptoms (group B).

Diagnosis of asthma and assessment of asthma severity was performed according to Global Initiative for Asthma (GINA) criteria [12]. In particular, asthma was defined in the presence of a history of recurrent attacks of reversible dyspnoea with wheezing, and bronchial hyperreactivity to methacholine.

In order to establish the degree of asthma severity and the requirement for regular treatment, in a preliminary evaluation each subject recorded asthma symptoms and peak expiratory flow (PEF) measurements in the early morning and in the evening during a 1-week period, after withdrawal of regular treatment and using only inhaled salbutamol as rescue medication. PEF variability was expressed as mean value of the maximal amplitude (highest-lowest/ daily mean) of each day of monitoring. The score of asthma symptoms (for each day: from 0 to 4 for nocturnal symptoms, and from 0 to 5 for diurnal symptoms) and the use of rescue salbutamol were expressed as weekly sum of the scores obtained in all days of monitoring. At the end of the week of PEF monitoring they measured FEV1, FVC and bronchial hyperresponsiveness to methacholine.

The main clinical and functional findings of the two groups of subjects are reported in table 1. The study was approved by the Hospital Medical Ethic Committee, and informed consent was obtained from all participants or their parents

\section{Study protocol}

All subjects were free from upper respiratory infection at least 6 weeks before the study. Patients in group B withdrew treatment $72 \mathrm{~h}$ before each study day.

Exposures were administered in a single-blind manner. All subjects were randomly exposed to $\mathrm{O}_{3}(0.26 \pm$ $0.04 \mathrm{ppm}$ ) or filtered air (sham) for $2 \mathrm{~h}$ in a challenge chamber on two different days, at least 1 week apart (median (range): $14(7,28)$ days), while exercising on a cycloergometer at work load predetermined to produce a ventilation rate of $25 \mathrm{~L} \cdot \mathrm{min}^{-1} \cdot \mathrm{m}^{-2}$ of body area surface. All of them attended the laboratory at 8:00 h on three different days. On day 1 they performed the cycloergometer workload test to establish the target work load inducing a ventilation rate near $25 \mathrm{~L} \cdot \mathrm{min}^{-1} \cdot \mathrm{m}^{-2}$. On days 2 and 3 they were exposed to $\mathrm{O}_{3}$ or filtered air for $2 \mathrm{~h}$. The sequence of exposure was: air-ozone in six subjects, ozone-air in eight subjects. Before the exposure, and 1 and $2 \mathrm{~h}$ after the beginning of the exposure they performed pulmonary function tests (PFT) using a computerized water-sealed bell spirometer (Biomedin, Padova, Italy) and a questionnaire was completed. Each subject was asked to grade from $0(0=$ no symptom $)$ to 4 ( $4=$ worst symptom) the severity of each symptom: cough, shortness of breath, tearing, eyes burning, throat and nose irritation, chest pain on deep inspiration, headache, dizziness, nausea, confusion, and sweat-ing. A total symptom score (TSS) was computed for each subject as the sum of all single symptom scores. Six hours after the end of both chamber exposures, PFT and HS sputum induction were conducted.

Table 1. - Anthropometric and functional data of the 14 asthmatic subjects examined

\begin{tabular}{|c|c|c|c|c|c|c|c|c|c|c|}
\hline \multirow{2}{*}{$\begin{array}{l}\text { Subject } \\
\text { No. }\end{array}$} & \multirow{2}{*}{ Sex } & \multirow{2}{*}{$\begin{array}{l}\text { Age } \\
\text { yrs }\end{array}$} & \multirow{2}{*}{$\begin{array}{l}\text { Height } \\
\mathrm{cm}\end{array}$} & \multirow{2}{*}{$\begin{array}{c}\text { FEV1 } \\
\%\end{array}$} & \multirow{2}{*}{$\begin{array}{c}\text { FVC } \\
\%\end{array}$} & \multirow{2}{*}{$\begin{array}{l}\text { PD20 } \\
\text { mg }\end{array}$} & \multirow{2}{*}{$\begin{array}{c}\mathrm{MA} \\
\%\end{array}$} & \multicolumn{2}{|c|}{ ASS } & \multirow{2}{*}{$\begin{array}{c}\text { RS } \\
\text { puffs }^{-} \text {week }\end{array}$} \\
\hline & & & & & & & & Night & Day & \\
\hline \multicolumn{11}{|l|}{ Group A } \\
\hline 1 & $\mathrm{M}$ & 24 & 184 & 103 & 93 & 0.272 & 3 & 0 & 2 & 2 \\
\hline 2 & $\mathrm{M}$ & 29 & 173 & 105 & 106 & 0.204 & 1 & 1 & 0 & 0 \\
\hline 3 & $\mathrm{~F}$ & 35 & 154 & 99 & 87 & 0.607 & 2 & 1 & 1 & 0 \\
\hline 4 & $\mathrm{M}$ & 22 & 173 & 102 & 90 & 0.300 & 6 & 0 & 3 & 2 \\
\hline 5 & M & 25 & 186 & 78 & 100 & 0.112 & 3 & 0 & 2 & 0 \\
\hline 6 & $\mathrm{M}$ & 15 & 190 & 92 & 103 & 0.202 & 2 & 0 & 2 & 0 \\
\hline 7 & M & 19 & 175 & 121 & 110 & 0.220 & 4 & 0 & 2 & 1 \\
\hline Mean \pm SD & & $24.0 \pm 6.5$ & $176 \pm 11.9$ & $100 \pm 13.1$ & $98.4 \pm 8.6$ & & $3.6 \pm 1.5$ & $0.3 \pm 0.5$ & $2 \pm 0.8$ & $0.7 \pm 0.9$ \\
\hline GM & & & & & & 0.274 & & & & \\
\hline \multicolumn{11}{|l|}{ Group B } \\
\hline 1 & $\mathrm{M}$ & 35 & 172 & 71 & 81 & 0.101 & 8 & 9 & 6 & 16 \\
\hline 2 & M & 20 & 171 & 116 & 110 & 0.170 & 5 & 4 & 4 & 6 \\
\hline 3 & $\mathrm{M}$ & 18 & 170 & 106 & 114 & 0.166 & 13 & 7 & 6 & 4 \\
\hline 4 & $\mathrm{M}$ & 31 & 183 & 111 & 102 & 0.031 & 7 & 2 & 8 & 4 \\
\hline 5 & M & 41 & 168 & 117 & 104 & 0.815 & 6 & 4 & 2 & 4 \\
\hline 6 & M & 40 & 170 & 81 & 94 & 0.028 & 10 & 4 & 5 & 9 \\
\hline 7 & $\mathrm{M}$ & 23 & 169 & 84 & 94 & 0.220 & 7 & 4 & 6 & 10 \\
\hline Mean \pm SD & & $29.7 \pm 9.4$ & $171.8 \pm 5.1$ & $98 \pm 18.8$ & $99.8 \pm 11.7$ & & $8 \pm 2.7 *$ & $4.8 \pm 2.3 *$ & $5.2 \pm 1.9 *$ & $7.6 \pm 1.9 *$ \\
\hline GM & & & & & & 0.174 & & & & \\
\hline
\end{tabular}

FEV1: forced expiratory volume in one second; FVC: forced vital capacity; PD20: provocative dose of methacholine causing a $20 \%$ fall in FEV1 from baseline; MA: maximal amplitude; ASS: weekly asthma symptom score; RS: rescue salbutamol; GM: geometric mean; *: $\mathrm{p}<0.05$, in comparison with group A. 


\section{Methods}

Challenge chamber. The subjects were exposed for 120 min in a $9 \mathrm{~m}^{3}$ static challenge chamber made of glass and aluminium [15], while exercising on a stationary cycloergometer for $20 \mathrm{~min}$ every hour. Mean air temperature was $21 \pm 1^{\circ} \mathrm{C}$ and the relative humidity was $45 \pm$ $5 \%$. Ozone was generated by a corona discharge $\mathrm{O}_{3}$ generator (Rancon Instruments, Milan, Italy) connected to a cylinder of purified air. $\mathrm{O}_{3}$ output into the chamber was $0.5 \mathrm{~L} \cdot \mathrm{min}^{-1}$. An $\mathrm{O}_{3}$ analyser (Photometric $\mathrm{O}_{3}$ Analyser 400, Rancon Instruments) connected to the chamber by a tubing circuit, continuously monitored gas concentration in the chamber. Mean $\pm \mathrm{SD} \mathrm{O}_{3}$ concentration was $0.26 \pm 0.04 \mathrm{ppm}$. A fan in the chamber ensured adequate gas mixing and circulation.

Hypertonic saline inhalation test and sputum processing. HS solution was nebulized with an ultrasonic nebulizer $\left(2.8 \mathrm{~mL} \cdot \mathrm{min}^{-1}\right.$ output; Sirius, Technomed, Firenze, Italy) and was inhaled for $5 \mathrm{~min}$ periods for up to 30 min. $\mathrm{NaCl}$ concentration was increased at 10-min intervals from 3 to 4 to $5 \%$. Every $5 \mathrm{~min}$ after the start of nebulization, patients were asked to rinse their mouth and throat carefully in order to discard saliva, and to try to cough sputum into a clean container; then FEV1 was measured. Nebulization was stopped after $30 \mathrm{~min}$ or when FEV1 fell by $\geq 20 \%$ from baseline. The functional response to HS inhalation was expressed as maximum FEV1 fall after HS inhalation ( $\triangle \mathrm{FEV} 1-\mathrm{HS} \%)$.

Sputum was processed as previously reported [16]. The whole sputum sample was diluted with an equal volume of $0.1 \%$ dithiotreithol (Sputasol; Unipath, Basingstoke, UK). The sample was incubated in a shaking bath at $37^{\circ} \mathrm{C}$ for $20 \mathrm{~min}$, then gently mixed to further dissolve mucus plugs. At the end of incubation, sample was filtered through a $53 \mu \mathrm{m}$ nylon gauze to remove debris. An aliquot of sputum sample was cytocentrifuged for 5 min (Cytospin; Shandon Scientific, Sewickley, PA, USA) and stained with Diff-Quik (Baxter Scientific Products, Miami, FL, USA). Two investigators, blinded to the subject's history, each first counted at least 500 cells on each sputum slide so as to obtain the squamous cell percentage as an indicator of saliva contamination. Cytospin slides on which 500 nonsquamous cells could not be counted were considered unsatisfactory and discarded. At least 500 nonsquamous cells were then counted on satisfactory slides. All cell percentages were averaged to give the final values reported. Macrophage, lymphocyte, neutrophil, and eosinophil percentages are expressed as percentage of total inflammatory cells, excluding squamous cells. The remainder of the sputum sample was centrifuged at $450 \times g$ for $10 \mathrm{~min}$. The supernatant was collected and stored at $-80^{\circ} \mathrm{C}$ for the analysis of soluble markers. The cell pellets were resuspended in normal saline for total cell counts with Turk staining and cell viability assessment by Trypan blue exclusion in a haemocytometer.

In the laboratory, this method gives a reasonably good reproducibility of inflammatory cell counts in sputum induced by HS. The reproducibility has been evaluated in 20 stable mild-to-moderate asthmatic subjects who repeated HS inhalation on two different days, a week apart, in a stable condition. The intraclass correlation coefficients $\left(r_{i}\right)$ between two measurements were: +0.90 for macrophage,
+0.23 for lymphocyte, +0.88 for neutrophil, and +0.82 for eosinophil percentage [17].

Eosinophilic cationic protein level in sputum supernatant. This was measured by means of a specific radioimmunoassay (RIA; Pharmacia RIA, Uppsala, Sweden). This method has been proven highly specific and sensitive (lower detection limit: $<2 \mu \mathrm{g} \cdot \mathrm{L}^{-1}$ ) with high intraand interassay reproducibility.

Interleukin-8 level in sputum supernatant. Antigenic interleukin (IL)-8 levels in sputum supernatants were quantified using a sandwich enzyme-linked immunosorbent assay (ELISA). Briefly, undiluted and serial dilutions of the sputum supernatants and standard human recombinant IL-8 (R\&D, Minneapolis, MN, USA) were placed into microtitre plates (Immulon, Chantilly, VA, USA) precoated with goat anti-human IL-8 antibody (R\&D) diluted 1:2,000. After incubation for $1.5 \mathrm{~h}$, rabbit anti-human IL-8 antibody (Upstate Biotechnology, Lake Placid, NY, USA) diluted 1:3,000 was added. After additional incubation for $1.5 \mathrm{~h}$, peroxidase conjugated goat anti-rabbit antibody (ICN Biomedicals, Costa Mesa, CA, USA) was added at a 1:2,000 dilution. $o$-Phenylenediamine (OPD) in a $0.01 \% \mathrm{H}_{2} \mathrm{O}_{2}$ solution was used as the substrate. The absorbance was measured at $492 \mathrm{~nm}$. The lower limit of IL-8 detectable by this assay is 10 pM. All samples were assayed in duplicate, and the mean value was considered.

\section{Statistical analysis}

FVC and FEV1 (as \% of the predicted value), TSS, maximum $\% \mathrm{FEV} 1$ fall and duration of $\mathrm{HS}$ inhalation are expressed as mean $\pm \mathrm{SD}$. Differential cell percentages in induced sputum, eosinophil cationic protein (ECP) and IL8 levels in the supernatant of induced sputum are expressed as median and range, while total inflammatory cells were examined as mean \pm SD.

Paired t-tests were used to compare FVC and FEV1 values, and TSS pre- and postexposure to air with the same values obtained after $\mathrm{O}_{3}$ exposure. Analysis of variance (ANOVA) tests were used to compare FVC, FEV1 and TSS at the different time-points after both air and $\mathrm{O}_{3}$ exposures. Cell percentages, ECP and IL-8 levels in induced sputum were compared between air and $\mathrm{O}_{3}$ exposure by using nonparametric Wilcoxon test.

A comparison of functional and biological data between two groups, both after air and after $\mathrm{O}_{3}$ exposure, was performed by ANOVA test or by Mann-Whitney test, as appropriate.

\section{Results}

\section{Clinical and functional evaluation}

Pre-exposure values of FVC, FEV1 and TSS were not significantly different between air and $\mathrm{O}_{3}$ exposures in both groups (table 2). Both FVC and FEV1 measured at the end of 1 and 2-h exposure and $6 \mathrm{~h}$ after the end of $\mathrm{O}_{3}$ exposure were significantly lower than FVC and FEV1 measured at the same time-points after air exposure in 
Table 2. - Mean \pm SD values of forced expiratory volume in one second (FEV1), forced vital capacity (FVC), total symptom score (TSS) and $\triangle$ FEV1-hypertonic saline (HS)\% before and at different time-points after exposure to ozone and air

\begin{tabular}{lcccc}
\hline & \multicolumn{2}{c}{$\begin{array}{c}\text { Group A } \\
\text { Mild intermittent }\end{array}$} & \multicolumn{2}{c}{$\begin{array}{c}\text { Group B } \\
\text { Mild persistent }\end{array}$} \\
\cline { 2 - 4 } & Ozone & Air & Ozone & Air \\
\cline { 2 - 4 } FEV1 pre-exposure \% & $91.0 \pm 15$ & $93.1 \pm 14$ & $96.0 \pm 13$ & $95.1 \pm 14$ \\
FEV1 1 h \% & $88.2 \pm 7.1$ & $96.7 \pm 9.2^{*}$ & $93.3 \pm 15$ & $98.0 \pm 14.7$ \\
FEV1 2 h \% & $82.1 \pm 12$ & $98.6 \pm 15^{*}$ & $92.8 \pm 12$ & $98.6 \pm 11^{*}$ \\
FEV 1 6 h \% & $89.7 \pm 12$ & $99.1 \pm 12^{*}$ & $87.5 \pm 16$ & $96.0 \pm 12.3$ \\
FVC pre-exposure \% & $93.4 \pm 9.2$ & $94.1 \pm 9.9$ & $96.0 \pm 8.3$ & $97.1 \pm 9.3$ \\
FVC 1 h \% & $89.2 \pm 7.2$ & $94.4 \pm 9.1^{*}$ & $97.1 \pm 7.7$ & $97.7 \pm 7.7$ \\
FVC 2 h \% & $84.4 \pm 10^{\S}$ & $97.5 \pm 11^{*}$ & $94.6 \pm 6.4$ & $95.4 \pm 8.2$ \\
FVC 6 h \% & $89.7 \pm 8.2$ & $95.6 \pm 9.8^{*}$ & $99.7 \pm 9.1$ & $1.7 \pm 8.2$ \\
TSS pre-exposure & $3 \pm 2.7$ & $2.8 \pm 2.8$ & $1.4 \pm 0.9$ & $1.0 \pm 1.4$ \\
TSS 1 h & $7.3 \pm 3.1^{\S}$ & $2.7 \pm 2.6^{*}$ & $2.7 \pm 1.6$ & $5.1 \pm 3^{\S}$ \\
TSS 2 h & $10 \pm 5.5^{\S}$ & $4.8 \pm 5.2^{*}$ & $23.3 \pm 9.7$ & $2.1 \pm 0.2$ \\
$\Delta$ FEV 1-HS & $33.1 \pm 19.7$ & $30 \pm 12.8$ & $20.1 \pm 8.9$ \\
\hline
\end{tabular}

$\triangle \mathrm{FEV} 1-\mathrm{HS} \%$ : maximum FEV1 fall after HS inhalation. ${ }^{*}: \mathrm{p}<0.05$, between air and ozone exposure (by paired t-test). ${ }^{\S}: \mathrm{p}<0.05$, with respect to pre-exposure (by ANOVA test).

mild intermittent asthmatic subjects. In mild persistent asthmatic subjects there were no significant differences for FVC and FEV1 between post-air and post- $\mathrm{O}_{3}$ exposure, except at $2 \mathrm{~h}$ for FEV1 (table 2, fig. 1a and b).

Similar results were obtained when TSS was considered. After 1 and $2 \mathrm{~h}$ of $\mathrm{O}_{3}$ exposure TSS significantly increased when compared with air exposure in group A subjects, but not in group B subjects (table 2). When compared with preexposure evaluation, TSS increased after 1 and 2-h $\mathrm{O}_{3}$ exposure in group A subjects, and only at $2 \mathrm{~h}$ in group B subjects. No changes were observed in TSS after air exposure in either of the two groups examined.
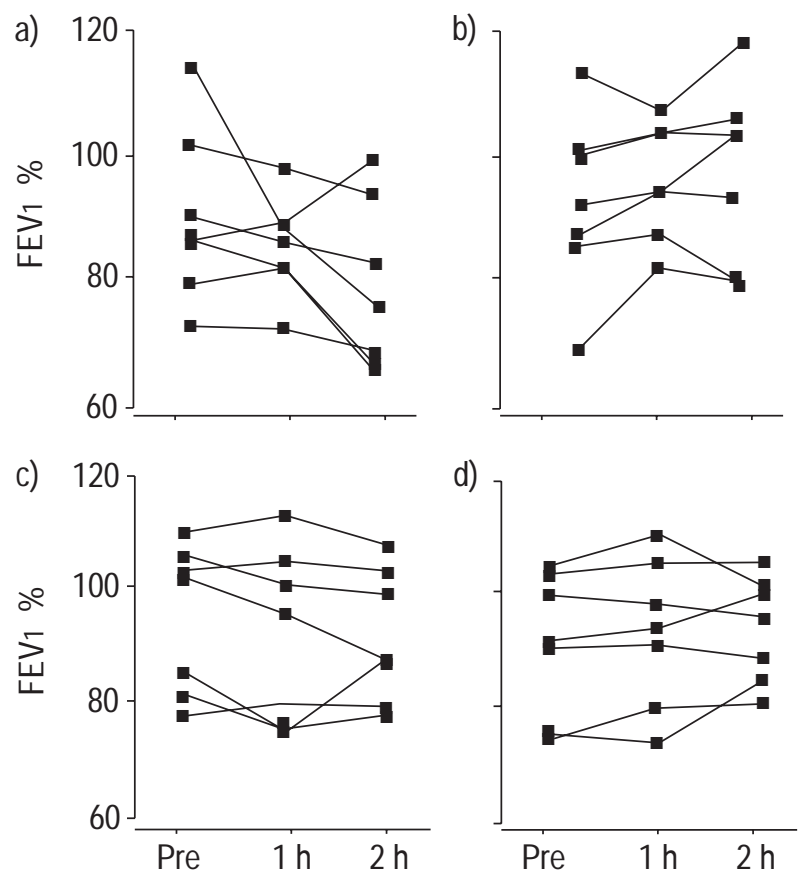

Fig. 1. - Individual values of forced expiratory volume in one second (FEV1) measured before (Pre), 1 and $2 \mathrm{~h}$ after the beginning of ozone (a and c) and air exposure (b and d) in mild intermittent asthmatic subjects $(a$ and $b$ ) and in mild persistent asthmatic subjects ( $c$ and $d)$.
There was no significant difference in maximum FEV1 fall following $\mathrm{HS}$ inhalation between air and $\mathrm{O}_{3}$ exposure (table 2).

\section{Cell percentages and soluble markers in induced sputum}

Median values of sputum inflammatory cell percentages after air exposure were similar in the two groups (table 3).

The percentage of sputum neutrophils was significantly higher $6 \mathrm{~h}$ after $\mathrm{O}_{3}$ exposure compared with air exposure in all subjects, in those with mild intermittent asthma (group A) and in those with mild persistent asthma (group B) (table 3), and the increase was consistent in each subject (fig. 2). The sputum eosinophil percentage, which was already high after air exposure, decreased after $\mathrm{O}_{3}$ exposure in both groups of subjects, probably owing to the increase in neutrophil percentages; the difference was, however, not significant (table 3 ).

The median value of total inflammatory cells in the induced sputum was not different between air and $\mathrm{O}_{3}$ exposure in both groups examined (group A: $4.92 \pm$ $2.71 \times 10^{6}$ versus $3.51 \pm 4.43 \times 10^{6}$; group $\mathrm{B}$ : $2.47 \pm 1.93$ $\times 10^{6}$ versus $3.50 \pm 1.93 \times 10^{6}$, after air and $\mathrm{O}_{3}$ respectively) nor the percentage of noninflammatory squamous cells (group A: 24\% (4.6-67.6) versus 35\% (4.8-74); group B: $33 \%(13-72)$ versus $26 \%(2.4-71)$ after air and $\mathrm{O}_{3}$ respectively).

There was no significant change in ECP levels in the sputum supernatant obtained after either air or $\mathrm{O}_{3}$ exposure in both groups $\left(298.8 \mu \mathrm{g} \cdot \mathrm{L}^{-1}(103-1887)\right.$ versus $238 \mu \mathrm{g} \cdot \mathrm{L}^{-1}$ (75.4-4250) for group $\mathrm{A} ; 160.1 \mu \mathrm{g} \cdot \mathrm{L}^{-1}(123.32-449.36)$ versus $324.2 \mu \mathrm{g} \cdot \mathrm{L}^{-1}$ (129.1-917.4) for group $\left.\mathrm{B}\right)$.

IL-8 levels were significantly higher in sputum supernatant collected $6 \mathrm{~h}$ after the end of $\mathrm{O}_{3}$ exposure than after air exposure in mild intermittent asthmatic subjects, but not in mild persistent asthmatic subjects (fig. 3). IL-8 levels after air exposure were not significantly different between two groups.

\section{Discussion}

These results show that exposure to $0.26 \mathrm{ppm}$ of ozone for $2 \mathrm{~h}$ elicits in untreated mild intermittent asthmatic 
Table 3. - Median values (range) of sputum cell percentages after air and ozone exposure in the two groups examined

\begin{tabular}{|c|c|c|c|c|}
\hline & \multicolumn{2}{|c|}{$\begin{array}{c}\text { Group A } \\
\text { Mild intermittent }\end{array}$} & \multicolumn{2}{|c|}{$\begin{array}{c}\text { Group B } \\
\text { Mild persistent }\end{array}$} \\
\hline & Ozone & Air & Ozone & Air \\
\hline Macrophages & $23.5(2.4-61.2)$ & $43.3(17-75.3)$ & $31.9(15.1-69)$ & $57.3(16.8-81.8)$ \\
\hline Lymphocytes & $0.8(0-1.8)$ & $0(0-4.3)$ & $0.3(0-1)$ & $9(0-1.5)$ \\
\hline Neutrophils & $70.2(28-87)$ & $26.6(8.6-73.2)^{*}$ & $62.1(25-82.4)$ & $27.9(14.4-39.6)^{*}$ \\
\hline Eosinophils & $4.3(0-31.6)$ & $14(3-36.8)$ & $2.8(2-34.9)$ & $10(3.1-56.1)$ \\
\hline
\end{tabular}

*: $p<0.05$, between post-air and post-ozone exposure.

subjects a greater airways response than in treated mild persistent asthmatic subjects, both in terms of clinical and functional response, and in terms of biochemical and cellular changes in induced sputum.

The pro-inflammatory activity of $\mathrm{O}_{3}$ on human airways is well known. Up until now most human studies used BAL as a research tool to investigate the airway inflammatory response to $\mathrm{O}_{3}$ exposure. Regarding healthy subjects, a significant increase in percentage of neutrophils in BAL fluid has been found $6-18 \mathrm{~h}$ after $\mathrm{O}_{3}$ exposure [7, 18]. The strongest evidence of $\mathrm{O}_{3}$-induced airway injury in normal subjects has been given by ARIS et al. [19] who demonstrated by histological data an increase in neutrophils in $\mathrm{O}_{3}$-exposed bronchial tissue compared with that exposed to air. More recently, both BASHA et al. [9] and SCANNELL et al. [10] also used BAL in asthmatic subjects to study inflammatory response to $\mathrm{O}_{3}$ exposure. They demonstrated that $\mathrm{O}_{3}$ elicits a greater inflammatory response in asthmatics than in normal subjects.

Only few studies have used the analysis of the induced sputum to investigate the airways inflammatory response to outdoor pollutants [11, 20, 21]. FAHY et al. [21] showed that exposure of healthy subjects to $0.4 \mathrm{ppm} \mathrm{O}_{3}$ for $2 \mathrm{~h}$ was associated with significantly greater increases in sputum neutrophil percentage and in myeloperoxidase (MPO) concentration than air exposure. HiLTERMANN et al. [11] demonstrated that exposure to $0.4 \mathrm{ppm} \mathrm{O}_{3}$ for $2 \mathrm{~h}$ induced a significant increase in sputum neutrophils in normal and in mild asymptomatic asthmatic subjects. The present data confirm that the pre-existing eosinophilic inflammation was not increased by ozone exposure in asthmatic subjects, as shown by the lack of increase in eosinophil percentage
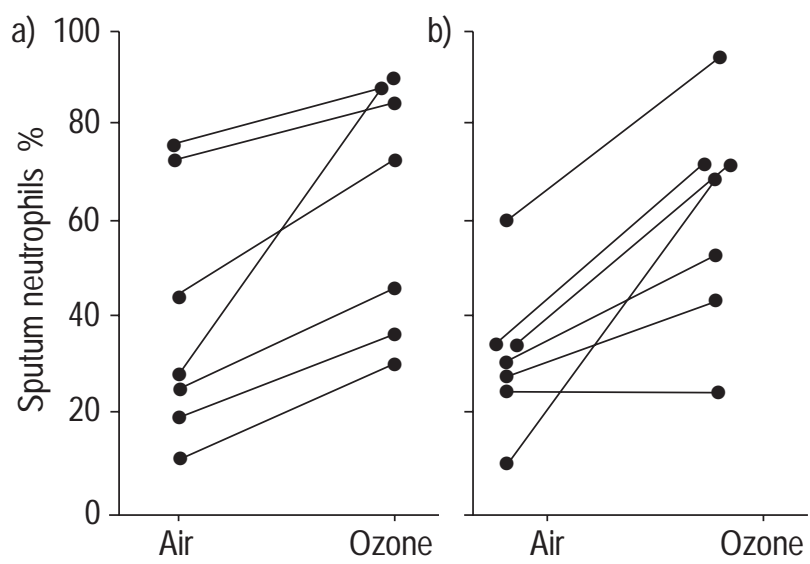

Fig. 2. - Individual values of sputum neutrophil percentages after air and after ozone in a) mild intermittent asthmatic subjects (group A) and b) mild persistent asthmatic subjects (group B). and ECP levels in the induced sputum obtained after $\mathrm{O}_{3}$ exposure.

Most previous studies have examined the effect of $\mathrm{O}_{3}$ on mild asymptomatic asthmatic subjects not requiring regular treatment. In this category of patient, the results of the present study are in agreement with those obtained by other authors. Different data was obtained in mild persistent asthmatic subjects who required regular treatment with inhaled corticosteroids and long-acting $\beta_{2}$-agonists for the relief of symptoms. The presence of daily asthma symptoms was confirmed in this group by PEF and symptom monitoring conducted preliminarily during a short-term withdrawal of regular treatment. In this group of patients, a significant increase in sputum neutrophils was not accompanied by a significant increase in sputum IL-8 concentration and was associated with a mild change in FVC, FEV1 and TSS in comparison with untreated mild intermittent asthmatic subjects. To the best of the authors' knowledge, no previous study has compared the effect of $\mathrm{O}_{3}$ in groups of subjects with different asthma severity.

The mild effect of $\mathrm{O}_{3}$ on regularly treated asthmatics cannot be ascribed to a direct effect of antiasthma drugs on acute airway response to $\mathrm{O}_{3}$, because treatment was withdrawn $72 \mathrm{~h}$ before $\mathrm{O}_{3}$ exposure. It cannot be excluded that a longer withdrawal of antiasthma drugs before $\mathrm{O}_{3}$ exposure could have determined different results. This washout time period was chosen for two reasons: 1) to avoid any direct effect of antiasthma drugs on the airway response to ozone; and 2) subjects were not able to withdraw asthma treatment for a longer period of time. Preious
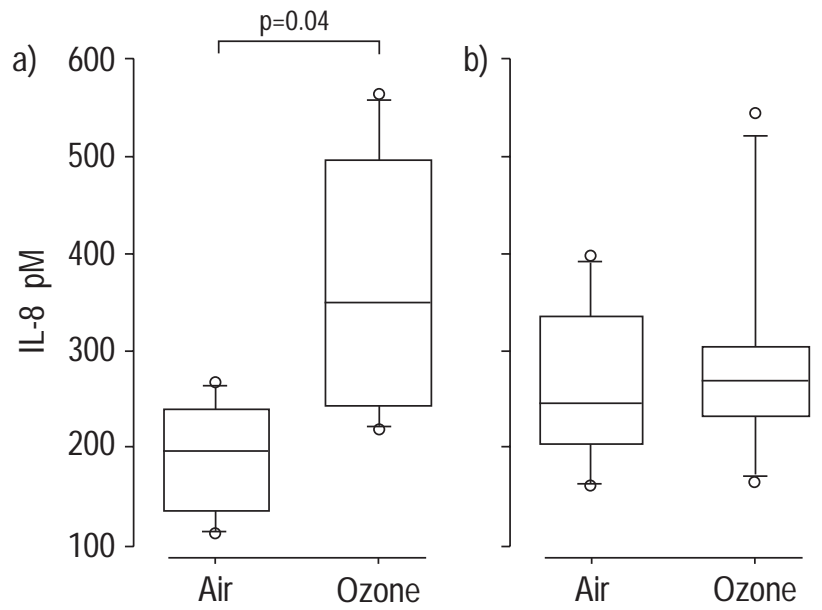

Fig. 3. - Median values, interquartiles, 90th percentiles and range of interleukin (IL)-8 concentrations in the sputum supernatant after air and ozone in a) mild intermittent asthmatic subjects (group A) and b) mild persistent asthmatic subjects (group B). 
studies have used similar wash-out periods [22]. By contrast, it is possible that long-term treatment with inhaled corticosteroids could have changed the pattern of the airway response to $\mathrm{O}_{3}$, and this different reactivity could persist some days after the withdrawal of treatment. An effect of budesonide on $\mathrm{O}_{3}$-induced airway inflammation has been demonstrated in dogs [23]. Inhaled corticosteroids have been reported to increase the level of neutral endopeptidase (NEP) in bronchial mucosa, to improve vascular permeability and to modulate the expression of adhesion molecules on epithelial and endothelial cells [24]. All these mechanisms are presumed to be involved in the inflammatory response of the airways to inhaled oxidants such as $\mathrm{O}_{3}$ [25]. This hypothesis should be investigated by a different study protocol.

Few studies have reported the influence of antiasthma drugs, such as systemic steroids on the airway response to $\mathrm{O}_{3}[26,27]$, showing no significant effect. Only indomethacin has been demonstrated to be able to prevent a functional airway response to $\mathrm{O}_{3}$ in humans [28]. However, all these studies concerned normal subjects and a short course of treatment; therefore, the lack of pre-existing airway inflammation and the short duration of treatment could have determined the failure in preventing $\mathrm{O}_{3^{-}}$ induced airway inflammation by antiasthma drugs.

A further possible explanation of the milder airway response to $\mathrm{O}_{3}$ in subjects with mild persistent asthma could be a greater activity of antioxidant properties in the airway mucosa in subjects with more severe airway inflammation. This hypothesis has not been confirmed, and some previous studies did not show any difference in the antioxidant levels in bronchial or nasal lavage of subjects with different airway response to inhaled oxidants $[29,30]$.

A further explanation of the difference in the increase of symptom score after $\mathrm{O}_{3}$ between the two groups could be due to a blunted perception of dyspnoea and other irritant symptoms of the upper airways in subjects with mild persistent asthma in comparison with patients with mild intermittent asthma [31].

The discrepancy between the increase in sputum neutrophils and the lack of increase in sputum IL- 8 in mild persistent asthmatics suggests that chemotactic factors other than IL-8 could be involved in the recruitment of neutrophils in the airways after $\mathrm{O}_{3}$ exposure. In vitro studies have shown the release of several chemotactic factors, including leukotriene $\mathrm{B}_{4}$, from epithelial cells exposed to $\mathrm{O}_{3}$ [32].

The sample size of the examined subjects was low in this study, but not different from that reported in several previous studies $[4,6,11,21]$. There was also a small nonsignificant difference in the mean age of the two groups. A lower airway response in older subjects has been reported, but it was evident in healthy adults $>50$ yrs of age [33], and the relationship between FEV1 changes and age was weak [34].

The asthmatic subjects were not pretreated with inhaled $\beta_{2}$-agonist before HS inhalation to assess the airway responsiveness to hypertonic challenge. At the time of the study, all subjects had an FEV1 in the normal range, and reported occasional asthma symptoms. In these subjects, maximum fall in FEV1 after HS inhalation was well tolerated. However, as recommended by several authors, $\beta_{2}$-agonist pretreatment is mandatory in stable asthmatics, as well as in the presence of airway obstruction or severe bronchial hyperresponsiveness [35].

In conclusion, it was demonstrated that the degree of airway response to a short-term exposure to ozone is different in asthmatic subjects, depending on the severity of the disease and the requirement of regular anti-inflammatory treatment. Both the functional response and the increase in interleukin- 8 sputum concentration were reduced in subjects with mild persistent asthma in comparison with subjects with mild intermittent asthma. The available data do not allow us to define whether this difference depends on the severity of the disease or on the regular antiinflammatory treatment.

\section{References}

1. Romieu I, Meneses F, Ruiz S, et al. Effects of air pollution on the respiratory health of asthmatic children living in Mexico City. Am J Respir Crit Care Med 1996; 154: 300307.

2. Schwartz J. Air pollution and hospital admissions for the eldery in Detroit, Michigan. Am J Respir Crit Care Med 1994; 150: 648-655.

3. Holtzman MJ, Cunningham JH, Sheller JR, Irsigler GB, Nadel JA, Boushey HA. Effect of ozone on bronchial reactivity in atopic and nonatopic subjects. Am Rev Respir Dis 1979; 120: 1059-1067.

4. Kreit JW, Gross KB, Moore TB, Lorenzen TJ, D'Arcy J, Eschenbacher WL. Ozone-induced changes in pulmonary function and bronchial responsiveness in asthmatics. $J$ Appl Physiol 1989; 66(1): 217-222.

5. Molfino NA, Wright SC, Katz I, et al. Effect of low concentrations of ozone on inhaled allergen responses in asthmatic subjects. Lancet 1991; 338: 199-203.

6. Jorres R, Nowak D, Magnussen H. The effect of ozone exposure on allergen responsiveness in subjects with asthma or rhinits. Am J Respir Crit Care Med 1996; 153: 56-64.

7. Koren HS, Devlin RB, Graham DE, et al. Ozone-induced inflammation in the lower airways of human subjects. $\mathrm{Am}$ Rev Respir Dis 1989; 139: 407-415.

8. Linn WS, Shamoo DA, Anderson KR, Peng RC, Avol EL, Hackney JD. Effects of prolonged, repeated exposure to ozone, sulfuric acid, and their combination in healthy and asthmatic volunteers. Am J Respir Crit Care Med 1994; 150: 431-440.

9. Basha MA, Gross KB, Gwizdala CJ, Haidar AH, Popovich J. Bronchoalveolar lavage neutrophilia in asthmatic and healthy volunteers after controlled exposure to onzone and filtered purified air. Chest 1994; 106: $1757-1765$.

10. Scannell C, Chen L, Aris RM, et al. Greater ozoneinduced inflammatory responses in subjects with asthma. Am J Respir Crit Care Med 1996; 154: 24-29.

11. Hiltermann TJ, Stolk J, Hiemstra PS, et al. Effect of ozone exposure on maximal airway narrowing in non asthmatic and asthmatic subjects. Clin Sci 1995; 89: 619624.

12. National Institutes of Health. Global Initiative for Asthma. NIH publication 1995; No. 95: 3659 January.

13. Pizzichini E, Pizzichini MMM, Efthimiadis A, et al. Indices of airway inflammation in induced sputum: reproducibility and validity of cell and fluid-phase measurements. Am J Respir Crit Care Med 1996; 154: 308317. 
14. Hargreave FE, Popov J, Kidney J, Dolovich J. Sputum measurements to assess airway inflammation in asthma. Allergy 1993; 48: 81-83.

15. Paggiaro PL, Vagaggini B, Dente FL, et al. Bronchial hyperresponsiveness and toluene diisocyanate: long-term change in sensitized asthmatic subjects. Chest 1993; 103: $1123-1128$.

16. Bacci E, Cianchetti S, Paggiaro PL, et al. Comparison between hypertonic and isotonic saline-induced sputum in the evaluation of airway inflammation in subjects with moderate asthma. Clin Exp Allergy 1996; 26: 1395-1400.

17. Bacci E, Cianchetti S, Bartoli ML, et al. Reproducibility of induced sputum cell analysis in the evaluation of airway inflammation in asthma. Eur Respir J 1996; 9: Suppl. 23, 119s (abstract).

18. Schegle ES, Siefkin AD, McDonald RJ. Time-course of ozone-induced neutrophilia in normal humans. Am Rev Respir Dis 1991; 143: 1353-1358.

19. Aris RM, Christian D, Hearne PQ, Kerr K, Finkbeiner KWE, Balmes JR. Ozone induced airway inflammation in human subjects as determined by airway lavage and biopsy. Am Rev Respir Dis 1993; 148: 1363-1372.

20. Vagaggini B, Paggiaro PL, Giannini D, et al. Effect of short-term $\mathrm{NO}_{2}$ exposure on induced sputum in normal, asthmatic and COPD subjects. Eur Respir J 1996; 9: 1852-1857.

21. Fahy JV, Wong HH, Llu JT, Boushey HA. Analysis of induced sputum after air and ozone exposures in healthy subjects. Environ Res 1996; 70: 70-72.

22. Linn WS, Anderson KR, Shamoo DA, et al. Controlled exposures of young asthmatics to mixed oxidant gases and acid aerosol. Am J Respir Crit Care Med 1995; 152: 885-891.

23. Stevens WHM, Adelroth E, Woolley MJ, Wattie J, Dahlback M, O'Byrne PM. The effects of an inhaled corticosteroid on oxygen radical production by bronchoalveolar cells after allergen or ozone in dogs. Eur J Pharmacol Environ Toxicol Pharmacol Sec 1995; 293: 251-257.

24. Brattsand R, Pipkorn U. Glucocorticoids. Experimental approaches. In: Kaliner MA, Barnes PJ, Persson CGA, eds. Asthma. Its Pathology and Treatment. New York, Marcel Dekker Inc., 1991; pp. 667-709.

25. Chitano P, Hosselet JJ, Mapp CE, Fabbri LM. Effect of oxidant air pollutants on the respiratory system: insights from experimental animal research. Eur Respir J 1995; 8: 1357-1371.

26. Bottei GM, Devlin RB, Bromberg PA, Peden DB. The effect of corticosteroids on lower airways inflammation and pulmonary function after ozone exposure (abstract). Am J Respir Crit Care Med 1995; 151 (4, part 2): A28.

27. Gong H Jr, Bedi JF, Horvath SM. Inhaled albuterol does not protect against ozone toxicity in nonasthmatic athletes. Arch environ Health 1988; 43: 46-53.

28. Ying RL, Gross KB, Terzo TS, Eschenbacher WL. Indomethacin does not inhibit the ozone induced increase in bronchial responsiveness in human subjects. Am Rev Respir Dis 1990; 142: 817-821.

29. Mudway I, Kelly FJ, Krishma T, et al. Upper airways loss of uric acid during exposures to ozone. Eur Respir J 1996; 9: Suppl. 23; 415s (abstract).

30. Lund $\mathrm{K}$, Dunster $\mathrm{C}$, Refsnes $\mathrm{M}$, et al. Antioxidant response in lung lining fluid of subjects exposed to hydrogen fluoride. Eur Respir J 1996; 9: Suppl. 23; 416s (abstract).

31. Barnes PJ. Poorly perceived asthma. Thorax 1992; 47: 408-409.

32. Leikauf GD, Driscoll KE, Wey HE. Ozone-induced augmentation of eicosanoid metabolism in epithelial cells from bovine trachea. Am Rev Respir Dis 1988; 137: 435442.

33. Commitee of Environmental and Occupational Health Assembly of ATS. Health effects of outdoor air pollution. State of the Art. Am J Respir Crit Care Med 1996; 153: 350 .

34. McDonnel WF, Muller KE, Bromberg PA, Shy CM. Predictors of individual differences in acute response to ozone exposure. Am Rev Respir Dis 1993; 147: 818-825.

35. Wong HH, Fahy JV. Safety of one method of sputum induction in asthmatic subjects. Am J Respir Crit Care Med 1997; 156: 299-303. 